\title{
Ectopic craniopharyngioma of the orbit: illustrative case
}

\author{
Albin A. John, MBA, ${ }^{1}$ Harrison Marsh, MBA, ${ }^{1}$ Stephen S. Rossettie, MBA, ${ }^{1}$ Coby N. Ray, MD, MS, MBA, ${ }^{2}$ \\ Kenn A. Freedman, MD, $\mathrm{PhD},{ }^{2}$ and Benedicto $\mathrm{C}$. Baronia, $\mathrm{MD}^{3}$
}

Departments of ${ }^{1}$ Surgery, ${ }^{2}$ Ophthalmology, and ${ }^{3}$ Neurosurgery, Texas Tech University Health Sciences Center, Lubbock, Texas

BACKGROUND Craniopharyngiomas are uncommon malformations of the sellar or parasellar region that are partly cystic and calcified and have low histological grade. The typical age of presentation is bimodal, with peak incidence rates in children at age 5 to 14 years and in adults at age 50 to 74 years. The usual clinical manifestations are related to endocrine deficiencies due to mass effect along with visual impairment and increased intracranial pressure. If a tumor is favorably localized, the treatment of choice is complete resection.

OBSERVATIONS The authors presented a unique case of a 61-year-old man with a suspicious cystic lesion in the right orbital roof that was causing right-sided headaches with pressure and pain in the right eye. Both computed tomography and magnetic resonance imaging were used for further evaluation and showed a suspicious lytic bone lesion that had an epicenter within the orbital rim, which was highly suggestive of a tumor of interosseous origin. After removal, the tumor was identified by pathology as a craniopharyngioma.

LESSONS The importance of this case report is in documenting a unique case of an ectopic craniopharyngioma in the orbit, adding to current hypotheses of the pathogenesis of ectopic craniopharyngiomas, and presenting an extensive review of literature.

https://thejns.org/doi/abs/10.3171/CASE21544

KEYWORDS ectopic craniopharyngioma; orbit; de novo craniopharyngioma

Craniopharyngiomas (CPs) are low-incidence, cystic, benign brain tumors stemming from the remnants of the Rathke's pouch, an invagination at the roof of the developing mouth that gives rise to the adenohypophysis, or metaplasia of adenohypophysis pars tuberalis cells to squamous cell nests. ${ }^{1-4}$ These tumors can occur anywhere on the path of embryonic cell migration between the midline sphenoid bone and the floor of the sella turcica. ${ }^{1,2,5,6}$

CPs comprise $3 \%$ of all intracranial tumors and show a bimodal age, with the first peak occurring during childhood and a second peak occurring in the sixth decade of life. ${ }^{4}$ Presenting symptoms of $\mathrm{CP}$ in children include headache, visual disturbances, central diabetes insipidus symptoms, and growth stunting. Adults may present with a headache as well; however, presentation can also include decreased sexual function and hypothalamic dysfunction, especially in thermoregulation. ${ }^{1-4,7}$

The pituitary gland is made up of the adenohypophysis, neurohypophysis, and infundibular stalk. The adenohypophysis is an outpouching of oral ectodermal epithelium (Rathke's pouch) whereas the neurohypophysis and infundibular stalks are extensions of the diencephalon. By the fifth week of gestation, Rathke's pouch elongates and extends upwards and makes a pharyngo-hypophyseal stalk that separates from the oral epithelium between weeks 6 and 8 after meeting with the neurohypophysis. Rathke's cleft then involutes. However, the pharyngo-hypophyseal duct can persist in $\sim 33 \%$ of patients, leading to a persistent connection between the sellar floor and the vomer. . $^{8-10}$

Approximately $50 \%$ of these tumors originate at the level of the third ventricle within the infundibulum and may expand into the third ventricular cavity. ${ }^{1}$ It is uncommon for CPs to occur outside of this locality; however, cases have been documented of CPs at the cerebellopontine angle and other disparate locations. ${ }^{1,11}$ Differential diagnosis for CP includes germ cell tumors, pituitary tumors, and cysts of Rathke's pouch. ${ }^{1}$

There are two subtypes of CP: adamantinomatous craniopharyngioma $(A C P)$ and papillary craniopharyngioma (PCP). These subtypes differ by their age distribution and pathogenesis. ACPs are

ABBREVIATIONS ACP = adamantinomatous craniopharyngioma; $\mathrm{CP}=$ craniopharyngioma; $\mathrm{CSF}=$ cerebrospinal fluid; $\mathrm{CT}=$ computed tomography; $\mathrm{MRI}=$ magnetic resonance imaging; NCC = neural crest cell; PCP = papillary craniopharyngioma.

INCLUDE WHEN CITING Published February 7, 2022; DOI: 10.3171/CASE21544.

SUBMITTED September 20, 2021. ACCEPTED December 6, 2021.

(C) 2022 The authors, CC BY-NC-ND 4.0 (http://creativecommons.org/licenses/by-nc-nd/4.0/). 
the more common type overall whereas PCPs occur almost exclusively in adults. ${ }^{1}$ ACPs, which arise from an increased activation of the WNT pathway because of increased stability of $\beta$-catenin, are predominantly cystic and calcified and take up contrast in their walls. ${ }^{1,4}$ ACPs have densely packed cells interspersed with squamous cells, known as stellate reticulum. There are nodules of eosinophilic keratinous masses with cystic cavities that are lined by flattened epithelium. ACPs may also have Rosenthal fibers but should not be mistaken for pilocytic astrocytoma. ${ }^{2,4}$ PCPs, on the other hand, arise from BRAF V600E mutations and appear on imaging as monomorphous, palisading, noncalcified, and solid masses. $^{1,2,4}$

This case report and review of literature investigate a unique case of a primary craniopharyngioma originating within the right superolateral orbital roof. To investigate the prevalence of ectopic locations of craniopharyngiomas, an extensive literature review was conducted using the research databases PubMed, Cochrane Database, and Google Scholar from 1900 to 2021 . The search query used was adapted from that used by Gabel and colleagues. ${ }^{12}$ Search terms included "craniopharyngioma" and "ectopic" or "unusual" or "uncommon" and excluded "recurrent." The resulting search query yielded 69 results, of which 26 articles were included. Studies of craniopharyngiomas were included if the CP did not occur primarily within the third ventricle or sellar, parasellar, infrasellar, or suprasellar space. Radiological studies, malignant craniopharyngiomas, giant cell tumors, dermoid cysts, and ectopic recurrences of primary craniopharyngiomas were excluded.

\section{Illustrative Case}

The patient was a 61 -year-old obese (body mass index: $35.2 \mathrm{~kg} / \mathrm{m}^{2}$ ) man with a past medical history of anemia, chronic obstructive pulmonary disease, hypertension, hyperlipidemia, prostate biopsy in 2019 that was concerning for cancer, and surgical removal of lipomas in his left shoulder and right atrium of the heart.

The patient was initially referred by an ophthalmologist for an oculoplastics consultation regarding concern for a supraorbital lesion that presented with periodic pain around the right eye that was seen on a previous computed tomography (CT) scan. A subsequent CT scan showed a lytic bone lesion of the right orbit, which, in conjunction with patient's concerning prostate cancer, was suspicious for a malignant neoplasm. He also reported tinnitus and pressure in his right eye. He denied any changes in mental status or any visual disturbances.

\section{Ophthalmological Examination}

A comprehensive dilated eye examination was performed. The patient had 20/20 vision in both eyes with his current glasses (pseudophakia in the right eye) and had an intraocular pressure of $8 \mathrm{~mm} \mathrm{Hg}$ in the right eye and $7 \mathrm{~mm} \mathrm{Hg}$ in the left eye. He had full confrontational fields in both eyes with no obvious proptosis and full ocular motility. On further examination, tenderness to palpation at his superior orbit was appreciated. Slit lamp examination and dilated fundus examinations were noncontributory. The patient also had decreased forehead sensation on the right side.

\section{Imaging}

CT imaging, as seen in Fig. 1, showed an expansile lytic lesion $(21 \times 19 \times 13 \mathrm{~mm}$ [transverse $\times$ anteroposterior $\times$ craniocaudal] $)$ in the roof of the right orbit. Subsequent magnetic resonance imaging (MRI), as seen in Fig. 2, demonstrated a mildly T1 hyperintense and $\mathrm{T} 2$ hypointense nonenhancing lesion in this region.

The tentative plan to address the lesion involved a combined case with neurosurgery and oculoplastics that included orbital biopsy and total resection via a transcranial right supraorbital skull base approach.

\section{Surgical Procedure}

The patient received a stereotactic craniotomy using a right supraorbital skull base approach with gross removal of the orbital tumor, repair and reconstruction of the skull base, cranioplasty, and duroplasty. Using a neuronavigational system (Medtronic StealthStation), a supraorbital bone flap was created with simultaneous dural opening because of its tight adherence to the bone. The tumor was identified at the superior portion of the orbital rim. Coring of the tumor was performed, and a specimen was sent for pathologic determination. The remaining tumor was removed piecemeal. Both the skull base and the orbital roof were reconstructed using a MEDPOR implant (Stryker). A DuraMatrix (Stryker) duroplasty was performed at the skull base with overlying Gelfoam (Ethicon) to fill the cavity of the tumor. Titanium plates and screws were used to secure the bone, and bone cement was used to seal the reconstruction. After proper surgical closure, the patient was neurologically intact and was transferred to the neurosurgical intensive care unit. Blood loss
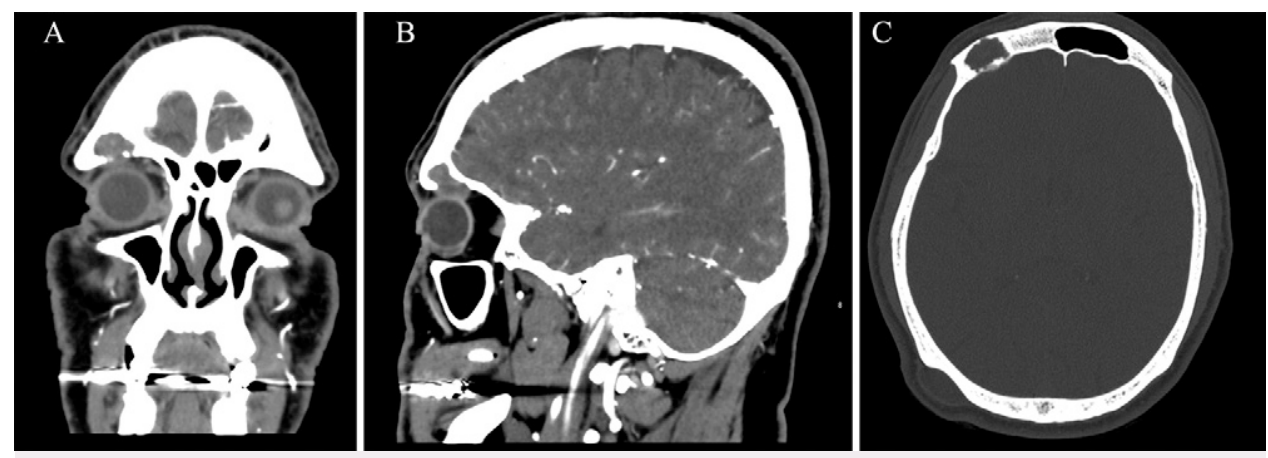

FIG. 1. Preoperative CT imaging. A-C: A lytic lesion involving the roof of the right orbit along with erosive changes along the inferior margin. There is minimal soft tissue component extending into the orbit and abutting the superior aspect of the right globe. 

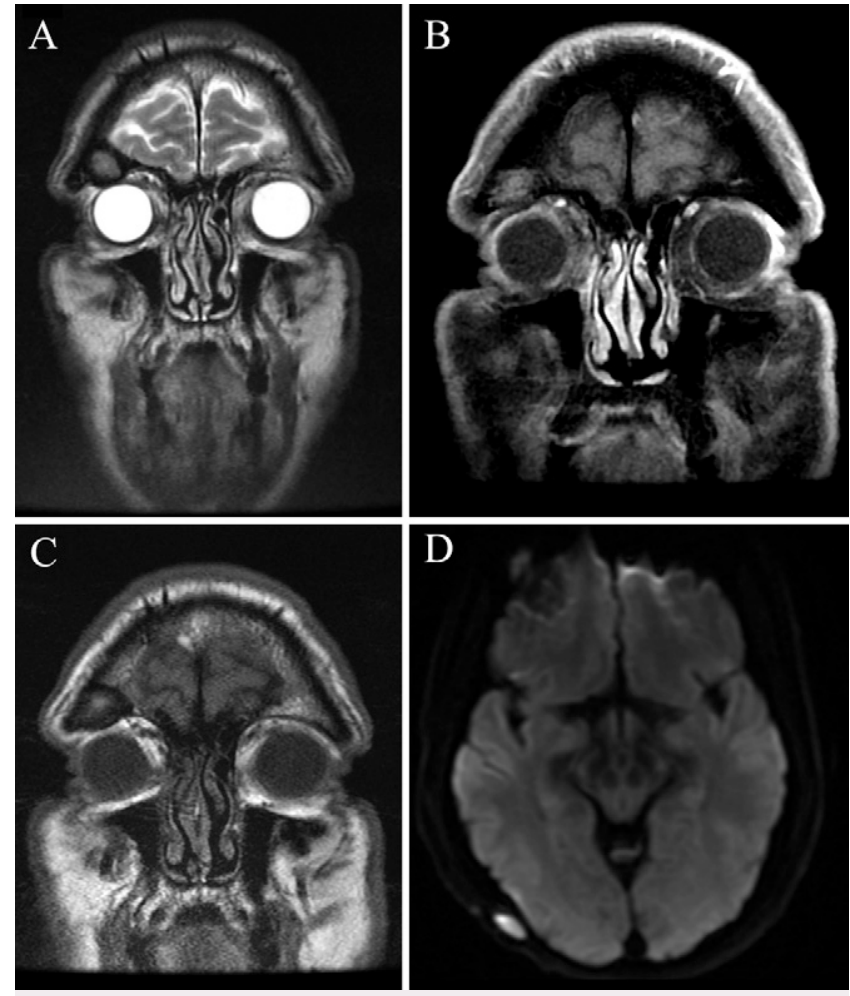

FIG. 2. Preoperative MRI demonstrates a mildly T2 hyperintense (A) and T1 hyperintense (B and $\mathbf{C}$ ) nonenhancing lesion within the roof of the right orbit. There is subtle abnormal restricted diffusion within this lesion (D).

during the procedure was $50 \mathrm{~mL}$. Postsurgical CT, as seen in Fig. 3 , demonstrated minimal pneumocephalus, no signs of intracranial hemorrhage, and an intact reconstruction of the orbital rim. Pathology of the orbital tumor specimen noted cholesterol crystals, giant cells, reactive fibrosis, focal hemorrhage, hemosiderin-laden macrophages, and calcifications most consistent with a diagnosis of craniopharyngioma, as seen in Fig. 4. Pan-cytokeratin staining showed focal positivity of epithelial components of the lesion. The level of Ki-67, a proliferation marker, was low. The patient had a benign postoperative course and was discharged on postoperative day 4 without any plans for radiation treatment. The patient will follow up with the neurosurgery department for a custom implant to address the orbital defect and assessment for possible recurrence.

\section{Postsurgical Outcome}

On follow-up examination with the ophthalmology department, our patient reported minimal discomfort and no changes to his vision. He denied eye or orbital pain and had no other reports. On examination, he had full ocular motility in both eyes; no ecchymosis or enophthalmos in the right eye; and equal, round, normally reactive pupils.

\section{Discussion}

Observations

Development of the Orbit

The orbit starts developing during the third intrauterine week via migration of neural crest cells (NCCs) from the maxilla and the

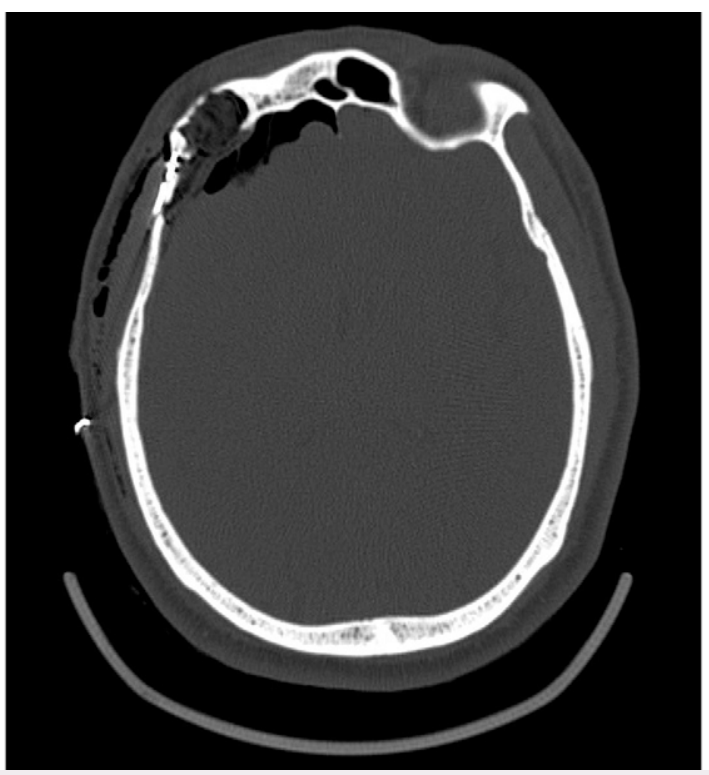

FIG. 3. Postoperative CT imaging demonstrates gross total resection of the lytic lesion involving the roof of the right orbit along with postsurgical changes of metallic plate reconstruction

frontonasal anlage. These migratory NCCs, influenced by the developing eye, brain, and face, meet at the optic stalk to form the orbit. $^{13,14}$ The NCCs undergo an epithelial-mesenchymal transition and differentiate into cranial bone, nerves, and connective tissues. Osteogenesis occurs during week 6 , and ossification starts at week 8 and ends around week 14. In contrast to the mesodermal origin of the parietal and occipital bones, the orbit is made from migrated NCCs that undergo both intramembranous and endochondral ossification (sphenoid and ethmoid bones only). ${ }^{14}$

\section{Craniopharyngioma of the Orbit}

Extensive literature review noted only one other ectopic craniopharyngioma at the orbit. A case report by Vitulli and colleagues noted an ectopic craniopharyngioma at the superior posterolateral compartment of the orbit with thinning of the lateral wall but no evidence of intracranial extension. ${ }^{13}$ Using an endoscopic transorbital approach, the CP was removed.

The CP presented in this study is different from that reported by Vitulli and colleagues because it originated in the roof of the right orbit. Origin of a CP in the frontal bone is highly unusual; however, its interosseus origin is best evidenced by review of this patient's surgical reports, tumor histology, and radiology. During resection of the tumor, the neurosurgeon noted that the tumor was soft, vascular, and easily suctioned, consistent with a CP. Furthermore, histology, as seen in Fig. 4, noted many features most consistent with a diagnosis of CP. Further deeper levels and $\beta$-catenin staining noted definite cytoplasmic focal positivity in the clusters of cells and minute foci of nuclear staining. Although chronic xanthogranulomatous inflammation and hematic cysts of the orbit may present similarly, supporting factors for the diagnosis of CP include presence of epithelial components in the lesion, lack of increase in serological inflammatory markers, and cystic lytic (bone) lesions on imaging. Other differentials, such as ameloblastoma and odontogenic cysts, are unlikely because our sample lacks 


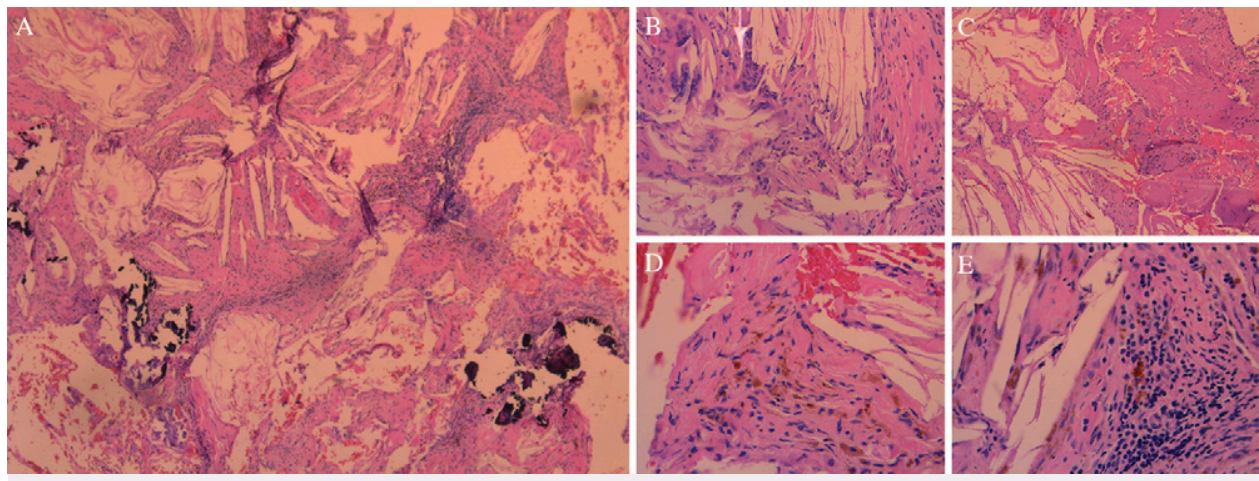

FIG. 4. A: Original magnification $\times 10$. Hematoxylin and eosin staining demonstrates cholesterol crystals, calcifications, and inflammation. B-E: Original magnification $\times 20$. Hematoxylin and eosin staining demonstrates cholesterol crystals (B and C), inflammation (C), hemosiderin-laden macrophages (D), and histiocytic giant cells (B). No evidence of high $\mathrm{N}: \mathrm{C}$ ratio cells indicative of metastatic tumors. Procedural hemorrhage noted (C and D).

the characteristic epithelial changes. Histologically, the constellation of findings in our sample is most consistent with a craniopharyngioma.

Upon review of the radiologic findings, as seen in Fig. 2, the epicenter of the $\mathrm{CP}$ is located within the right frontal bone, with scalloping of the frontal bone and erosive changes involving the roof of the orbit. MRI demonstrates an expansile appearance of the roof of the orbit along. Furthermore, the CP presented in this case is subtly hyperintense in T1-weighted imaging, a common characteristic in $\mathrm{CP}$ imaging, with no significant suppression on fat-suppressed imaging.

\section{Craniopharyngioma Development}

Many prevailing theories for ectopic craniopharyngiomas exist, including the embryonic/de novo theory, migratory theory, and metaplasia theory. The embryonic theory, one of the earliest and most established theories, proposes that CPs develop from remnants of the Rathke's pouch. The de novo theory, on the other hand, attributes CP development to totipotent or multipotent cells rather than embryonic remnants of the Rathke's pouch. However, both theories focus on development of CP from cells found along the line that extends from the vomer to the floor of the sella turcica through the sphenoid bone. ${ }^{6,15-22}$ The migratory theory focuses on diffuse spreading of cells throughout the suprasellar and sellar regions as a result of differing rates of cell multiplication during the rotation of the adenohypophsyis. ${ }^{10,23}$ This theory developed from accounts of remnants of the Rathke's pouch found on the posterior wall of the pharynx and sphenoid bone. $6,17-20,22,24-27$ Alternatively, the metaplastic theory aims to address CP development in adults whereby squamous epithelium of the Schneiderian membrane, derived from the oral ectoderm, undergoes metaplasia., ${ }^{5,10,19-22,28}$ Other researchers have found associations between congenital proliferative syndromes, such as Gardner syndrome, and CP formation because there is an increased $\beta$-catenin and persistent activation of WNT signaling pathways as a result of defective APC. ${ }^{13,29-31}$

Our review of the literature involving ectopic CPs, as described in Table 1, indicates that they are rare, with the cerebellopontine angle and nasopharynx as the first and second most common ectopic loci, respectively. ${ }^{12,32-36}$ When considering nasopharyngeal ectopic CPs, researchers currently hypothesize their development resulting from incomplete resorption of the Rathke's canal itself.
Aberrant anterior or posterior growth of the pars tuberalis is thought to contribute to this incomplete resorption, allowing embryonic remnants to persist at the posterior wall of the pharynx or other ectopic loci. $^{24,32,37}$

\section{Resection}

In our case, a transcranial approach that involved a craniotomy and unroofing of the orbit was performed so that the tumor could be removed without going through periorbita. Table 1 describes how previous cases of ectopic CP were surgically managed.

\section{Lessons}

Proposed Theory

A common factor among the disparate ectopic locations of CP is some modality of translocation, the foundation of our proposed theory. This theory differs from previously accepted migration theories because it emphasizes an external modality for translocation (e.g., cerebrospinal fluid [CSF] or NCC) rather than migration of the Rathke's pouch remnants themselves. Having reviewed multiple cases in literature of recurrent CPs as a result of CSF seeding, ${ }^{38-42}$ evidence indicates that ectopic craniopharyngiomas may occur as hamartomatous growths in various locations as a result of either CSF spreading or NCC migration that translocates squamous epithelia remnants from involution of Rathke's cleft or another idiopathic process. These seeds rest at favorable locations and later undergo metaplasia to form a CP..$^{10,20,40} \mathrm{CPs}$ like the one described in this study can also develop, as Vitulli postulates, as a result of sequestration and translocation of squamous epithelia by NCCs during their migration. ${ }^{13}$ Using mice models, the proposed translocation theory can be further investigated. Additional investigation into CSF cytology and a better understanding of NCC migration paths may also provide future direction in uncovering the pathogenesis of ectopic CPs.

Presented in this illustrative case report and extended review of literature is a unique case of a craniopharyngioma presenting at the orbital rim rather than the sellar or parasellar region. The tumor was managed via a joint neurosurgery and oculoplastic procedure that accomplished total resection via a craniotomy with unroofed orbital approach. Our case report and review add CPs to the list of orbital tumors, propose a unifying theory for ectopic CP pathogenesis, 
TABLE 1. Ectopic CP location, embryology, and surgical approach

\begin{tabular}{|c|c|c|c|}
\hline Authors \& Year & Ectopic Location & Embryological Origin & Surgical Removal Technique \\
\hline $\begin{array}{l}\text { Shah et al., } 20077^{5} \text { Algahtani } \\
\text { et al., } 2018^{19}\end{array}$ & Fourth ventricle & CSF cavity of rhombencephalon & Posterior fossa craniotomy \\
\hline Banczerowski et al., $2006^{6}$ & Rt temporobasal region & Forebrain ectoderm & Rt temporal craniotomy \\
\hline $\begin{array}{l}\text { Kim et al., } 2014{ }^{.29} \text { Yan et al., } \\
2009 ;{ }^{20} \text { Khalatbari et al., } \\
2012 ;^{28} \text { Gabel et al., } 2017 ;^{12} \\
\text { Zhou et al., } 2010^{33}\end{array}$ & Cerebellopontine angle & $\begin{array}{l}\text { CSF cavity between } \\
\text { metencephalon folds }\end{array}$ & Suboccipital craniotomy \\
\hline Ortega-Porcayo et al., $2015^{24}$ & Frontotemporal & Forebrain ectoderm & $\begin{array}{l}\text { Endoscopy; frontal lateral } \\
\text { approach }\end{array}$ \\
\hline $\begin{array}{l}\text { Bashir et al., 2009:18 Álvarez } \\
\text { Salgado et al., } 2017^{30}\end{array}$ & Posterior fossa & Mesoderm & Posterior fossa craniotomy \\
\hline Pourkhalili et al., $2016^{25}$ & Extradural & $\mathrm{N} / \mathrm{A}^{*}$ & Frontotemporal craniotomy \\
\hline Lee et al., $2011^{15}$ & Prepontine cistern & $\begin{array}{l}\text { CSF cavity anterior to } \\
\text { metencephalon }\end{array}$ & $\mathrm{N} / \mathrm{A}$ \\
\hline Sangiovanni et al., $1997^{26}$ & Corpus callosum & Diencephalon neuroectoderm & Interhemispheric approach \\
\hline $\begin{array}{l}\text { Lewin et al., } 19844^{34} \text { Benitez } \\
\text { et al., } 1988 ;^{9} \text { Wang et al., } \\
2001^{35}\end{array}$ & Nasopharynx & Cavity & $\begin{array}{l}\text { Ethmoidectomy; transpalatal } \\
\text { approach }\end{array}$ \\
\hline $\begin{array}{l}\text { Kawamata et al., 2002; } \\
\text { Langdon et al., 2018; } \\
\text { Horiuchi et al., } 2019^{39}\end{array}$ & Clivus & Occipital sclerotome, endochondral & Endoscopy; transphenoidal \\
\hline Smith et al., $2020^{22}$ & Anterior ethmoid sinus & Neural crest & Endoscopy \\
\hline Vitulli et al., $2021^{13}$ & W/in orbit & Neural crest & Transorbital/transcranial \\
\hline
\end{tabular}

* N/A, surgical resection method was not discussed.

and report an unusual case of a $\mathrm{CP}$ that grew within the orbital bone itself.

\section{Acknowledgments}

We would like to acknowledge Dr. Meenu Sharma from University Medical Center Department of Pathology and Dr. Roy Jacob from University Medical Center Department of Radiology for their assistance with pathology and imaging assistance, respectively, in this report.

\section{References}

1. Müller HL, Merchant TE, Warmuth-Metz M, Martinez-Barbera JP, Puget S. Craniopharyngioma. Nat Rev Dis Primers. 2019;5(1):75.

2. Müller HL. Craniopharyngioma. Endocr Rev. 2014;35(3):513-543.

3. Erfurth EM, Holmer H, Fjalldal SB. Mortality and morbidity in adult craniopharyngioma. Pituitary. 2013;16(1):46-55.

4. Chen C, Okera S, Davies PE, Selva D, Crompton JL. Craniopharyngioma: a review of long-term visual outcome. Clin Exp Ophthalmol. 2003;31(3):220-228.

5. Shah GB, Bhaduri AS, Misra BK. Ectopic craniopharyngioma of the fourth ventricle: case report. Surg Neurol. 2007;68(1):96-98.

6. Banczerowski P, Bálint K, Sipos L. Temporal extradural ectopic craniopharyngioma. Case report. J Neurosurg. 2007;107(1):178-180.

7. Kennedy HB, Smith RJ. Eye signs in craniopharyngioma. Br J Ophthalmol. 1975;59(12):689-695.

8. Yachnis AT. Craniopharyngioma: Embryology, pathology, and molecular aspects. In: Kenning TJ, Evans JJ, eds. Craniopharyngiomas. Academic Press; 2015:95-105.
9. Benitez WI, Sartor KJ, Angtuaco EJC. Craniopharyngioma presenting as a nasopharyngeal mass: CT and MR findings. J Comput Assist Tomogr. 1988;12(6):1068-1072.

10. Prabhu VC, Brown HG. The pathogenesis of craniopharyngiomas. Childs Nerv Syst. 2005;21(8-9):622-627.

11. Demaerel P, Moseley IF, Scaravilli F. Recurrent craniopharyngioma invading the orbit, cavernous sinus and skull base: a case report. Neuroradiology. 1993;35(4):261-263.

12. Gabel BC, Cleary DR, Martin JR, Khan U, Snyder V, Sang U H. Unusual and rare locations for craniopharyngiomas: clinical significance and review of the literature. World Neurosurg. 2017;98:381-387.

13. Vitulli F, D'Avella E, Solari D, et al. Primary ectopic orbital craniopharyngioma. Acta Neurochir (Wien). Published online August 31, 2021. doi: 10.1007/s00701-021-04969-y.

14. Tawfik HA, Dutton JJ. Embryologic and fetal development of the human orbit. Ophthal Plast Reconstr Surg. 2018:34(5):405-421.

15. Lee IH, Song CJ, Yeon JS, Kim SH, Song KS, Yeo MK. Craniopharyngioma in the prepontine cistern. AJNR Am J Neuroradiol. 2011;32(3):E57.

16. Solarski A, Panke ES, Panke TW. Craniopharyngioma in the pineal gland. Arch Pathol Lab Med. 1978;102(9):490-491.

17. Kawamata T, Kubo O, Kamikawa S, Hori T. Ectopic clival craniopharyngioma. Acta Neurochir (Wien). 2002;144(11):1221-1224.

18. Bashir EM, Lewis PD, Edwards MR. Posterior fossa craniopharyngioma. Br J Neurosurg. 2009;10(6):613-616.

19. Algahtani AY, Algahtani HA, Jamjoom AB, Samkari AM, Marzuk YI. De novo craniopharyngioma of the fourth ventricle: case report and review of literature. Asian J Neurosurg. 2018;13(1):62-65.

20. Yan Y, Tang WY, Yang G, Zhong D. Isolated cerebellopontine angle craniopharyngioma. J Clin Neurosci. 2009;16(12):1655-1657. 
21. Razmjoo S, Jazayeri SN, Bahadoram M, Barahman M. A rare case of craniopharyngioma in the temporal lobe. Case Rep Neurol Med. 2017;2017:4973560.

22. Smith $\mathrm{M}$, Wong $\mathrm{EH}, \mathrm{Ho} \mathrm{J}$, et al. Ectopic sinonasal craniopharyngioma arising from the anterior ethmoid sinus. Case report and literature review. Otolaryngology Case Reports. 2020;15(4):100151.

23. Garrè ML, Cama A. Craniopharyngioma: modern concepts in pathogenesis and treatment. Curr Opin Pediatr. 2007;19(4):471-479.

24. Ortega-Porcayo LA, Ponce-Gómez JA, Martínez-Moreno M, Portocarrero-Ortíz L, Tena-Suck ML, Gómez-Amador JL. Primary ectopic frontotemporal craniopharyngioma. Int J Surg Case Rep. 2015;9:57-60.

25. Pourkhalili R, Shekarchizadeh A, Seif B. Primary ectopic frontotemporal extradural craniopharyngioma. Adv Biomed Res. 2016;5(1):77.

26. Sangiovanni G, Tancioni F, Tartara F, et al. Ectopic craniopharyngioma: presentation of a case arising from the corpus callosum. Acta Neurochir (Wien). 1997;139(4):379-380.

27. Mishra SS, Behera SK, Senapati SB, Panigrahi S. Cystic craniopharyngioma of lateral ventricle with small stalk in suprasellar cistern: a rare case. Neurol India. 2013;61(4):434-436.

28. Khalatbari MR, Borghei-Razavi H, Samadian M, Moharamzad Y, Schick U. Isolated primary craniopharyngioma in the cerebellopontine angle. J Clin Neurosci. 2012;19(11):1516-1519.

29. Kim MS, Kim YS, Lee HK, Lee GJ, Choi CY, Lee CH. Primary intracranial ectopic craniopharyngioma in a patient with probable Gardner's syndrome. J Neurosurg. 2014;120(2):337-341.

30. Álvarez Salgado JA, González-Llanos Fernández de Mesa F, Villaseñor Ledezma JJ, et al. Ectopic craniopharyngioma and Gardner's syndrome: case report and literature review. (Article in Spanish.) Neurocirugia (Astur). 2017;28(2):97-101.

31. Hong CS, Omuro A, An Y, et al. Sporadic adamantinomatous craniopharyngioma with double-hit somatic APC mutations. Neurooncol Adv. 2021;3(1):b124.

32. Graziani N, Donnet A, Bugha TN, Dufour H, Figarella-Branger D, Grisoli F. Ectopic basisphenoidal craniopharyngioma: case report and review of the literature. Neurosurgery. 1994;34(2):346-349.

33. Zhou L, Luo L, Hui X, et al. Primary Rathke's cleft cyst in the cerebellopontine angle associated with apoplexy. Childs Nerv Syst. 2010;26(12):1813-1817.

34. Lewin R, Ruffolo E, Saraceno C. Craniopharyngioma arising in the pharyngeal hypophysis. South Med J. 1984;77(12):1519-1523.
35. Wang $Y X J$, Jiang $H, H e$ GX. Atypical magnetic resonance imaging findings of craniopharyngioma. Australas Radiol. 2001;45(1):52-57.

36. Langdon C, Santamaria-Gadea A, Rojas-Lechuga MJ, Mullol J, Alobid I. Clivus Rathke cleft cyst: case report of a rare disease and literature review. Rhinol Online. 2018;1(1):108-111.

37. Iwasaki K, Kondo A, Takahashi JB, Yamanobe K. Intraventricular craniopharyngioma: report of two cases and review of the literature. Surg Neurol. 1992;38(4):294-301.

38. Ito M, Jamshidi J, Yamanaka K. Does craniopharyngioma metastasize? Case report and review of the literature. Neurosurgery. 2001; 48(4):933-936.

39. Horiuchi D, Shimono T, Doishita S, Goto T, Tanaka S, Miki Y. Ectopic clival craniopharyngioma with intratumoral hemorrhage: a case report. Radiol Case Rep. 2019;14(8):977-980.

40. Frangou EM, Tynan JR, Robinson CA, Ogieglo LM, Vitali AM. Metastatic craniopharyngioma: case report and literature review. Childs Nerv Syst. 2009;25(9):1143-1147.

41. Liu JM, Garonzik IM, Eberhart CG, Sampath P, Brem H. Ectopic recurrence of craniopharyngioma after an interhemispheric transcallosal approach: case report. Neurosurgery. 2002;50(3):639-645.

42. Hoffmann A, Brentrup A, Müller HL. First report on spinal metastasis in childhood-onset craniopharyngioma. J Neurooncol. 2016;129(1): 193-194.

\section{Disclosures}

The authors report no conflict of interest concerning the materials or methods used in this study or the findings specified in this paper.

\section{Author Contributions}

Conception and design: John, Marsh, Rossettie, Baronia. Acquisition of data: John, Freedman, Baronia. Analysis and interpretation of data: John, Freedman, Baronia. Drafting the article: all authors. Critically revising the article: all authors. Reviewed submitted version of manuscript: all authors. Approved the final version of the manuscript on behalf of all authors: John. Administrative/technical/material support: Baronia. Study supervision: Ray, Baronia.

\section{Correspondence}

Albin A. John: Texas Tech University Health Sciences Center, Lubbock, TX. albin.john@ttuhsc.edu. 